\title{
Family Planning Policies and Their Impacts On the Poor: Peru's Experience
}

\author{
By James $N$. \\ Gribble, Suneeta \\ Sharma and Elaine \\ P.Menotti \\ James N. Gribble is \\ director of the \\ BRIDGE Project, \\ Population Reference \\ Bureau, Washington, \\ DC. Suneeta Sharma \\ is senior health \\ economist and \\ reproductive health \\ team leader, Health \\ Policy Initiative, \\ Constella Futures, \\ Washington, DC. \\ Elaine P. Menotti is \\ technical advisor, \\ U.S. Agency for \\ International \\ Development, \\ Washington, DC.
}

Although governments develop family planning policies to guide program design and implementation, these policies can have both intended and unintended consequences. As a result, policies may need periodic revision to achieve the desired outcomes. Over the last two decades, the government of Peru has instituted a series of laws and policies designed to enhance access to family planning services and commodities. In practice, these policies have not always had their desired effect. This paper examines the policies Peru's Ministry of Health has developed and implemented to promote access to family planning for all, and how those policies have affected contraceptive prevalence, method mix and source mix.

In this article, we review policies and laws relevant to family planning and provide insight on how the family planning policies have evolved and affected access to services, as well as how characteristics of and trends in the family planning market* have changed over time. Our assessment draws on multiple information sources, including family planning market segmentation data and literature on Peru's family planning program. Additional sources, such as ombudsman reports, user and provider interviews and health facility studies, clarify specific points.

A historic overview of key family planning policies and programs implemented in Peru, focusing on three time periods, 1985-1995, 1995-2000 and 2000-2004, provides information on policies that have been put in place and the degree to which they have affected access to family planning among the poor.

\section{Establishing Peru's Family Planning Program}

In 1983, as a result of available donor funds, a favorable political environment and the government's concern for population growth, the Ministry of Health began providing family planning services. It began with a vertical program that was relatively autonomous in program content and supervision and in use of financial resources and commodities. ${ }^{1}$ This effort was followed in 1985 by the establishment of the first National Population Policy, which stated that individuals and couples should be provided with information, health services and contraceptive methods, with the exception of voluntary sterilization, to assist them in making informed decisions about family size and fertility. ${ }^{2}$ Under the first National Family Planning Program

*The components of the family planning market include providers (government, social security, commercial, social marketing and nongovernmental organizations), consumers (women of reproductive age, 15-49years) and contraceptive methods (long-term and temporary modern methods).
(1987-1990), developed to implement the National Population Policy and financed by a combination of donor and government funds, the Ministry of Health coordinated public- and private-sector family planning programming and established goals for reductions in fertility and targets for increases in contraceptive use. Implementation of the program began in 1988, and despite political support, faced multiple challenges, including a national economic crisis, public-sector reorganization and the Ministry of Health's limited service delivery capacity; as a result, it was not implemented as broadly or as rapidly as envisioned. Despite the program's limitations, it contributed to a substantial reduction in the country's total fertility rate-from 4.1 in 1986 to 3.5 in $1991^{3}$-which was likely due to the increased availability of contraceptives, especially in rural areas. ${ }^{4}$

Peru's second National Family Planning Program (1991-1995), which also received considerable political commitment, continued to focus on expanding service delivery in underserved and predominantly rural areas. This expansion of services was financed by increased funding from government, which paid $20 \%$ of program costs, and donors, who paid $80 \% .{ }^{4}$ Annual government spending on health in general increased from 52 soles (US\$16) per capita during the late 1980 s to 59 soles (US\$18) per capita during the period 1991-1995. ${ }^{5}$ Meanwhile, annual donor investment in population-related activities in Peru increased from US\$5.2 million in 1987 to US\$12.9 million in 1994 and, spurred in part by the focus of the International Conference on Population and Development (ICPD) on family planning and donor priorities in the late 1990s, to US $\$ 28$ million in 1998. 6,7

In the early 1990s, in keeping with the worldwide trend of user fees in the public sector, most Ministry of Health facilities in urban areas charged clients for family planning services and products, while free family planning was available in rural areas, where the majority of the poor reside. In 1992, 41\% of women reported obtaining family planning products and services from the commercial sector (pharmacies and private providers), while 36\% obtained them from the Ministry of Health (see Figure 1). ${ }^{3}$ Social security and nongovernmental organizations served 18\% of women; precise information on method sources for the remaining 5\% was not available. The Ministry of Health's policy of targeting free services to poor people in rural areas and levying service fees in urban areas likely provided an opportunity for commercial family planning providers to thrive: Individuals who could afford to pay for family planning products and services may have found it more con- 
venient to purchase them from the numerous commercial outlets available and forgo the opportunity costs associated with using Ministry of Health facilities (i.e., distance, travel, quality of services).

\section{Family Planning for All}

In 1995, after the implementation of the ICPD Programme of Action (under which Peru is a signatory) and with political support from the president, the Ministry of Health instituted a policy to provide free family planning products and services to all who wanted them. Donors provided $100 \%$ of Ministry of Health contraceptive commodities, as well as substantial technical assistance and resources for training; supervision; information, education and communication; and other program components. As a result, the Ministry of Health was able to direct its resources to expansion of family planning service delivery. In 1994, the Ministry of Health introduced an ambitious program (Salud Básica) to expand its network of primary health care facilities, whose services included family planning. The number of health posts, health clinics and health centers run by the Ministry increased by more than 50\% between 1995 and 2000, and more than 10,000 medical and paramedical staff were added across the country. In addition, the legalization of female sterilization as a contraceptive method for all women in 1995 increased access to the method. ${ }^{8}$ Annual government spending on health increased from 59 soles (US\$18) per capita during the early 1990s to 93 soles (US\$29) per capita during the 1996-2000 period. ${ }^{5}$ As a result of both public-sector investments and donor support, the National Family Planning Program was delivering services through more than 6,000 facilities by the late 1990s. ${ }^{9}$

The expansion in service delivery and availability of free contraceptives in Ministry of Health facilities no doubt contributed to the increase in contraceptive prevalence from 41\% to 44\% between 1996 and 2000-Figure 2. Overall, women increased their use of modern methods from $27 \%$ to $32 \%$, with the poorest women increasing their modern method use from 18\% to 25\% (Figure 3, page 178). In addition, the policy was responsible for the dramatic increase in family planning market share for the Ministry of Health, which rose from $59 \%$ in 1996 to $68 \%$ in $2000 .^{10,11}$

At the same time, donors were beginning to reduce contraceptive commodity donations to the government of Peru, ${ }^{*}$ potentially threatening the availability of contraceptives. In response, the Peruvian government earmarked funds for family planning in its annual budget in 1997 and agreed to begin purchasing contraceptives in increasing quantities. The government's first purchase, however, was not made until two years later, in 1999, when funding for contraceptives was actually allocated for the first time, enabling the National Family Planning Program to purchase contraceptives through the United Nations Population

*On the basis of a combination of contraceptive prevalence, total fertility and economic indicators, donors had decided that Peru was ready to move toward more self-sustaining family planning efforts.
FIGURE 1. Among Peruvian women aged 15-49 practicing family planning, percentages obtaining services and methods from specific sources, 1992-2004

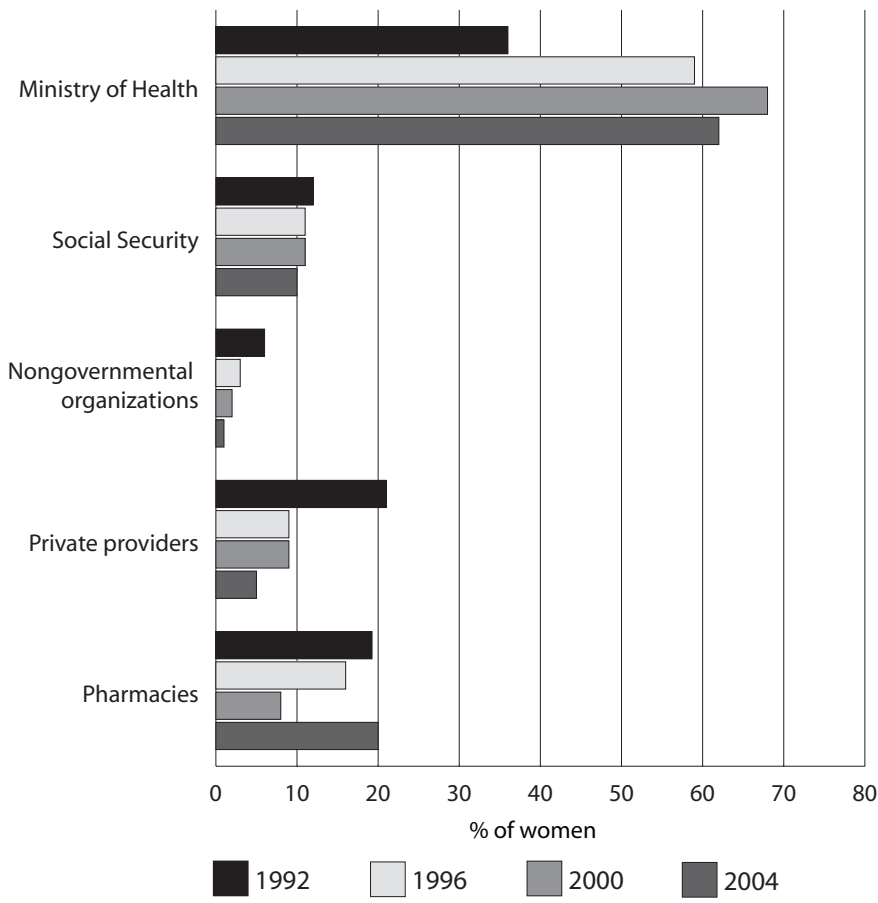

Fund's procurement mechanism. ${ }^{9}$

Between 1992 and 2000, a time in which Peru's public sector was assuming an increasingly dominant role in the family planning market, private providers found it difficult to compete with such widespread provision of free or highly subsidized products and services. ${ }^{12}$ The commercial sector's market share fell from 39\% to 17\% between 1992 and 2000. Between 1996 and 2000, the decline was driven primarily by a $50 \%$ drop in market share for pharmacies (from

FIGURE 2. Contraceptive prevalence, by type of method, among Peruvian women aged 15-49, by year, 1992-2004

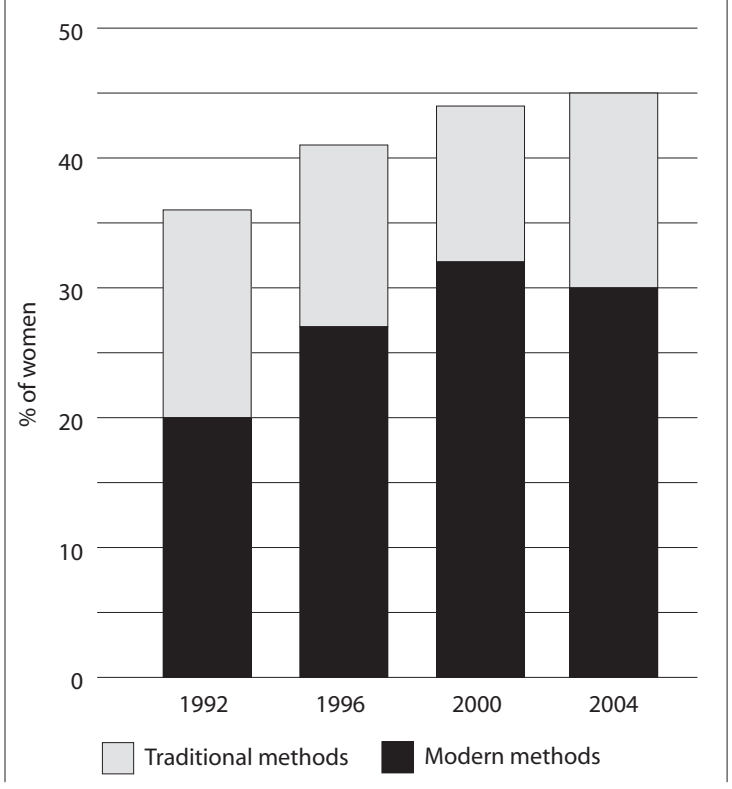


FIGURE 3. Contraceptive prevalence, by type of method, among Peruvian women aged 15-49 in the poorest and wealthiest quintiles, by year, 1996-2004

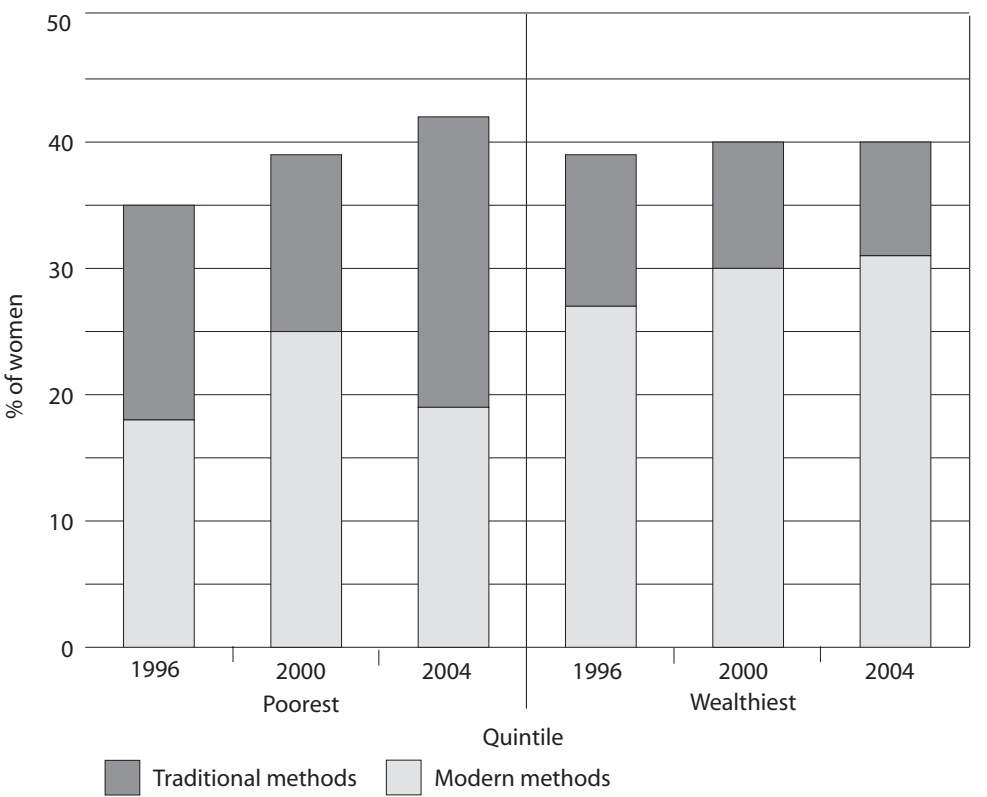

$16 \%$ to $8 \%){ }^{10,11}$ Total commercial sales of oral contraceptives and injectables decreased from 1.4 million units in 1995 to 1.1 million units in 1996-and continued to decline consistently until 2001. ${ }^{9}$

According to several studies, public-sector prices for temporary family planning methods are one of the major determinants of the use of commercial outlets for those methods. ${ }^{13-15}$ Their findings show that if high-quality contraceptive methods are available free of charge in Ministry

\section{FIGURE 4. Percentage distribution of Peru's Ministry of Health clients, by socioeconomic status, according to year, 1996-2004}

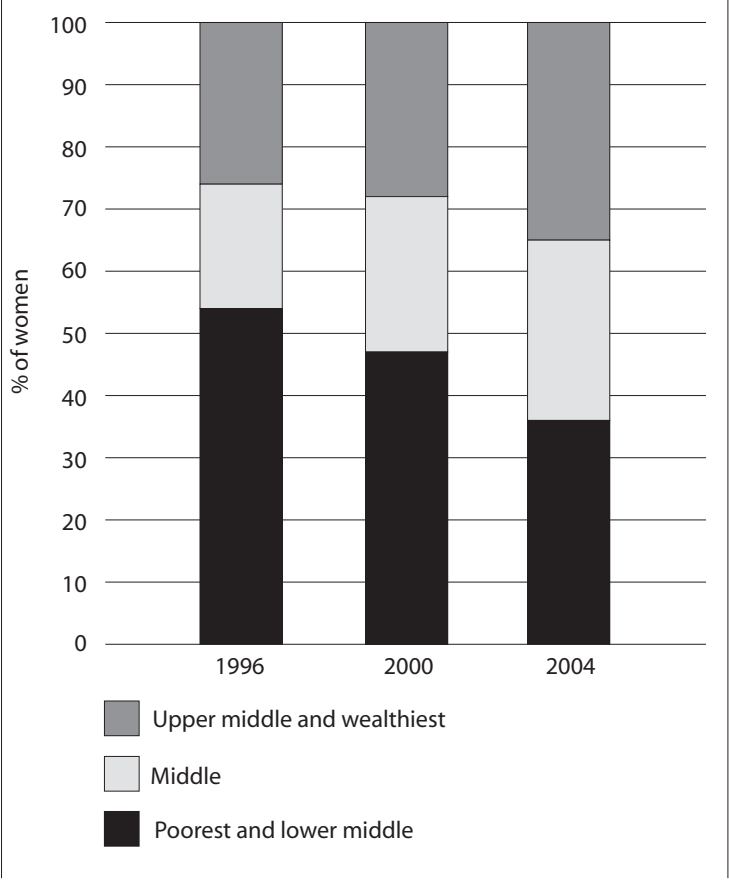

of Health facilities, private-sector users are likely to switch to these outlets. From 1996 to 2000, the share of Ministry of Health clients made up of women in the three upper socioeconomic quintiles rose from $46 \%$ to $53 \%$, while the share accounted for by women in the two lower quintiles decreased from $54 \%$ to $47 \%$ (Figure 4 ). ${ }^{*}$ Use of pharmacies for contraceptive supplies declined from $17 \%$ to $7 \%$ among women in the middle quintile and from $23 \%$ to $13 \%$ among those in the upper middle quintile. ${ }^{10,11}$ In other words, women with the ability to pay were benefiting from public subsidies.

The 1995 policy expanded access to family planning and initially adopted the focus of the ICPD Programme of Action on individual women's needs, instead of population control. In 1996, however, Peru's family planning program returned to employing the targets it had used when first established. ${ }^{16}$ By 1999, the government had changed its service delivery strategy and renounced the use of targets and quotas; measures were put in place to improve quality of care, including procedures to ensure informed consent for female sterilization. ${ }^{8}$

\section{Changes in Commitment to Family Planning}

At the beginning of the current decade, program changes within the Ministry of Health affected family planning's priority status on the national agenda. From 2000 to 2003, some government officials and prominent figures in the Ministry of Health who opposed family planning for moral reasons undertook deliberate measures to restrict access to family planning products, services and information in Peru. These measures included publicly disputing that condoms and IUDs were safe and effective, blocking commodity distribution and proposing modifications to the constitution and the general health law that would restrict access to family planning. 9,16

Although these government officials were not successful in altering or removing policies that supported Peruvians' access to family planning, their efforts coincided with the introduction of health sector reforms that affected the way in which family planning services were managed and delivered by the Ministry of Health. Since its inception in the 1980s, the National Family Planning Program had been vertically planned and managed by the Ministry of Health, as was the case for all other national health programs. At the service delivery level, family planning was provided by the Ministry's clinics, often having its own program administration and providers. In 2001, however, to improve efficiency and to reduce the costs of managing and delivering health services, the government combined all 14 national health programs into an integrated health model that was based on the life course and reorganized the Ministry of Health accordingly, decentralizing management func-

*Through a principal components analysis, a household's ability to pay for family planning is established using a standard of living index based on number of household assets. Households are then divided into quintiles (poorest, lower middle, middle, upper middle and wealthiest) according to standard of living. Here we calculated the standard of living index using the 1996, 2000 and 2004 Peru Demographic and Health Surveys. 
tions to the regions, eliminating separate budgets and downsizing or reassigning family planning staff to other Ministry of Health divisions. As a result, the Ministry of Health lost its core expertise in family planning at the central level, along with its ability to plan, supervise and monitor family planning services. ${ }^{9}$ The change in the model of care created barriers for family planning clientele, including less privacy, lack of educational materials, long waiting times and the requirement of a visit to the hospital or clinic pharmacy after consultation. ${ }^{1,17}$ Additionally, an economic crisis striking the country in the early 2000 s decreased per capita expenditures for health from 95 soles (US\$30) in 2001 to 88 (US\$27) in 2002 and 78 (US\$24) in 2003.5

During the same period, donors continued to reduce contraceptive commodity donations to the government of Peru. In 2002, as part of the donor contraceptive commodity phase-out plan, the government declared that contraceptives were strategic public health commodities, ${ }^{*}$ which helped to ensure that contraceptives received special protection and funding in the national budget. However, the government's inability to compensate for decreased donor funding left the Ministry of Health unable to meet the demand for contraceptives. As a result, from 2002 through 2004, government facilities experienced stockouts of contraceptives. Logistic problems, such as poor planning and information systems, a long supply chain and insufficient or incorrect commodity mix, exacerbated the problem.

After a steady increase during the previous decade, contraceptive use stagnated at 44\% in 2004, likely a result of stockouts and a weakened family planning program. Modern method use declined in 2004, especially among those in the poorest quintile, but stayed stable among the wealthiest quintile. Although use of traditional methods declined from $14 \%$ in 1996 to $12 \%$ in 2000 , their use rose again to $15 \%$ in 2004. This increase occurred in all quintiles except the wealthiest. In the poorest quintile, use of traditional methods increased from 14\% to 23\% between 2000 and 2004. ${ }^{18}$

Also between 2000 and 2004, Ministry of Health's market share shrank from $68 \%$ to $62 \%$; this was most likely due to the government's insufficient funding for commodities. Interestingly, during the same period, the commercial sector's market share rebounded from $17 \%$ to $25 \%$, dominated by pharmacies. The shift back to the commercial sector was led by women of the two wealthiest quintiles, who doubled their use of pharmacies between 2000 and 2004. ${ }^{11,18}$

Studies that focus on the experiences of public- and private-sector providers further elucidate the changes that took place in the Ministry of Health program between 2000 and 2004. One study found a decline in family planning services in the Ministry of Health, including an absence of follow-up, evaluation and training activities; a lack of regard for family planning and reproductive health as national priority issues by certain health officials and political leaders; and periods of stockouts of contraceptives that affected users for many months. ${ }^{19}$ The Ombudsman's Office reported consumer complaints about restricted ac- cess to contraceptive methods, which included a reduction in the availability of surgical contraception, limited access to information about contraceptives, stockouts of contraceptive methods and unauthorized fees for services that were supposed to be free in health centers. ${ }^{20}$

Perhaps as a result of reduced access to family planning services and commodity stockouts in Ministry of Health facilities, the reported number of abortions increased. About 35,000 cases of incomplete abortion were treated in Ministry of Health facilities in both 2000 and 2001; the number rose to 38,851 in 2002 and to 41,993 in 2003. ${ }^{19}$

Another study of family planning providers operating in Ministry of Health facilities, conducted between 2002 and 2004, provides further insight. ${ }^{21}$ In the 2002-2003 round of the study, $34 \%$ of the 238 providers interviewed reported that, in the 12 months prior to the survey, the method supply was continuous; $40 \%$ thought that the supply was sufficient and 25\% indicated that the supply was both continuous and sufficient. However, in the 2003-2004 round of the study, only $6 \%$ of 242 providers interviewed stated that the supply of contraceptives had been continuous; $17 \%$ thought the supply of methods was sufficient and $2 \%$ reported that the supply of methods was both continuous and sufficient. Also, in this round of the study, 83\% of providers said that when facing stockouts of contraceptive commodities-especially injectables and oral contraceptives-they advised their patients to use another method temporarily, with $60 \%$ providing a prescription to be filled at a commercial outlet or pharmacy and $23 \%$ changing the patient's contraceptive method to one in stock. These findings reveal not only reduced access, but also reduced quality of family planning services-which was likely to affect use-especially among women who could not afford commercial sector prices.

\section{DISCUSSION}

Peru's family planning policies have, in general, been designed to address all women's needs. Some policies, however, focus particularly on the poor, in accordance with the public sector's mandate to serve people whose access to and receipt of preventive and curative health services and products depends on subsidies and assistance. The evidence presented here suggests that the poor are particularly vulnerable to unanticipated policy outcomes, highlighting the need for well-designed policies and significant thought about both implementation and consequences. As Figure 4 shows, wealthier Peruvian woman made up an increasing share of government family planning clients between 1996 and 2004. This fact reveals a universal lesson: Given that developing countries have limited resources, providing universal coverage through the public sector, although conceptualized as a strategy to reach the poor, often ends

*Many of Peru's programs, such as those for tuberculosis, HIV/AIDS, and sexual and reproductive health, have been converted from vertical programs into "Health Strategies," interventions for which it is the responsibility of the government to carry out objectives. The Ministry of Health is therefore responsible for making available to the public the medicines and supplies critical to the success of these strategies. 
up serving a considerable proportion of people who can afford to pay for care and restricts access among those people who can least afford it.

In Peru, increasing service availability and providing free donated contraceptives through the Ministry of Health increased contraceptive prevalence for all women in the shortterm, but likely reduced the role of the commercial sector and shifted some wealthier clients to the Ministry of Health. The 1995 policy decision had the positive impact of increasing contraceptive use among women in the lowest two socioeconomic quintiles and those in rural areas. From 1996 to 2000 , women in the poorest quintile increased use of modern methods. However, from 2000 to 2004, use of modern methods declined in the poorest quintiles, and use of traditional methods among these groups increased. The general trend between 1996 and 2004 shows that the proportion of Ministry of Health clients from the wealthiest quintiles increased over time and that the proportion from the two poorest quintiles decreased. In light of the fact that the Ministry of Health's per capita financial resources have declined, priority should be given to refocusing those resources on the poorest groups, who have no other option for health services and products.

Although the overall trend in contraceptive prevalence shows a leveling off of modern method use from 2000 to 2004 , closer analysis by socioeconomic subgroups shows that the plateau in levels of use was not universal; use of modern methods declined in the two poorest quintiles between 2000 and 2004. A number of factors could explain why poor women-especially those in rural areas-decreased their use of modern contraceptives and increased their use of traditional methods: reduced access to family planning facilities, methods of choice or information in rural areas as a result of service integration; contraceptive stockouts in rural Ministry of Health facilities; levying of unofficial fees in public health centers; the inability to pay for methods in private-sector outlets; and the public discrediting of modern methods. Even if services for the poor were readily available, misinformation often affects women's interest in seeking family planning methods and services. A recent study conducted among rural, poor Peruvian women found that misinformation about family planning methods discourages contraceptive use; however, these women also indicated a strong interest in receiving information about family planning methods. ${ }^{22}$ These findings also suggest that for policies designed to improve access among the poor to be effective, they must also address a wider range of barriers that undermine utilization of services.

\section{Improving Access Among the Poor}

Currently, the government of Peru is taking steps to address the decline in modern method use among the poor and to improve access to accurate information. The use of conditional cash transfers, which is in the process of being implemented, and the expansion of services under social insurance programs may increase access to modern family planning methods among the poor.
- Conditional cash transfers. Peru is in the early stages of rolling out a conditional cash transfer program as part of a poverty alleviation strategy. To date, the program has been implemented in 14 of Peru's poorest regions. The program provides 100 soles monthly (approximately US\$31) to women who complete certain requirements, which include registering births, immunizing their children, obtaining prenatal care and supplementary nutrition and ensuring their children's school attendance. In addition, women have the opportunity to participate in information sessions on family planning and reproductive health.

- Social insurance programs. Peru has implemented a social insurance program that covers a range of curative and preventive health services for children, adolescents, pregnant women, the very poor and other vulnerable groups. In March 2007, the president of Peru and the minister of health signed a resolution to expand the package of benefits to include provision of family planning services and commodities. Given that the social insurance program is actually more successful in reaching the poor in general with its current care package than the Ministry of Health is in reaching the poor with family planning, ${ }^{23}$ it is a promising mechanism for ensuring that the poor have access to family planning information, services and methods.

\section{Conclusion}

Peru's experience reveals that when well-intentioned policies are implemented, they can have adverse outcomes on the people they are designed to help. Consequently, policymakers must think through both the short-and long-term consequences of policies prior to implementation. Moreover, as the experience of Peru demonstrates, they should continuously monitor and evaluate how policies are being implemented and be willing to make adjustments when it is clear that a policy is not achieving its desired outcomes.

\section{REFERENCES}

1. Subiria, G, Informe de disponibilidad asegurada de insumos anticonceptivos región Junín, internal document, Lima, Peru: Iniciativa de Políticas en Salud, 2006.

2. Sobrevilla LA, Peru: population and policy, Population Manager, 1987, $1(1): 40-44$

3. Instituto Nacional de Estadística e Informática, Asociación Benéfica PRISMA and Macro International, Perú Encuesta Demográfica y de Salud Familiar, 1991/1992, Columbia, MD, USA: Macro International, 1992.

4. Angeles G, Guilkey DK and Mroz TA, The determinants of fertility in rural Peru: program effects in the early years of the national family planning program, Journal of Population Economics, 2005, 18(2):367389.

5. Asociación Pro Derechos Humanos (APRODEH) and Centro de Asesoría Laboral del Perú (CEDAL), Informe Sobre la Situación de los Derechos Económicos, Sociales y Culturales 2002-2003: Dos Años de Democracia ... y i los DESC?, Lima, Peru: APRODEH and CEDAL, 2005.

6. United Nations Population Fund (UNFPA), Global Population Assistance Report 1995, New York: UNFPA, 1997.

7. UNFPA, Financial Resource Flows for Population Activities in 2004, New York: UNFPA, 2006.

8. Leon FR, Providers' Compliance with Quality of Care Norms, Lima, Peru: Population Council, 1999

9. Taylor PA et al., Peru: Contraceptive Security Assessment, September 1-12, 
2003, Arlington, VA: John Snow/DELIVER, and Washington, DC: Futures Group International/POLICY II, 2004.

10. Instituto Nacional de Estadística e Informática and Macro International, Perú Encuesta Demográfica y de Salud Familiar, 1996, Calverton, MD, USA: ORC Macro, 1996.

11. Instituto Nacional de Estadística e Informática and Macro International, Perú Encuesta Demográfica y de Salud Familiar, 2000, Calverton, MD, USA: ORC Macro, 2000.

12. Sharma S, Gribble JN and Menotti EP, Creating options in family planning for the private sector in Latin America, Pan American Journal of Public Health, 2005, 18(1):37-44.

13. Foreit KGF, Broadening commercial sector participation in reproductive health: the role of public sector prices on markets for oral contraceptives, Commercial Market Strategies Technical Paper Series, Washington, DC: Commercial Market Strategies, 2002, No. 3.

14. Bulatao R, What influences the private provision of contraceptives? Commercial Market Strategies Technical Paper Series, Washington, DC: Commercial Market Strategies, 2002, No. 2.

15. Winfrey W et al., Factors influencing the growth of the commercial sector in family planning service provision, POLICY Project Working Paper, Washington, DC: Futures Group International, 2000, No. 6.

16. Coe AB, From anti-natalist to ultra-conservative: restricting reproductive choice in Peru, Reproductive Health Matters, 2004, 12(24):56-69.

17. Sarley D et al., Options for Contraceptive Procurement: Lessons Learned from Latin America and the Caribbean, Arlington, VA, USA: DELIVER, and Washington, DC: USAID Health Policy Initiative, 2006.

18. Instituto Nacional de Estadística e Informática and Macro
International, Perú Encuesta Demográfica y de Salud Familiar, 2004, Calverton, MD, USA: ORC Macro, 2004.

19. Ferrando D, El aborto clandestino en el Perú: nuevas evidencias, PowerPoint presentation, Lima, Peru: Flora Tristan and Pathfinder International, 2004.

20. Defensoria del Pueblo, La anticoncepción quirúrgica y los derechos reproductivos III, casos investigados por la Defensoría del Pueblo, Informe Defensorial No. 69, Lima, Peru: Defensoria del Pueblo, 2002.

21. Proyecto POLICY/Peru, Encuesta de Proveedores de Planificación Familiar en el Ministerio de Salud, Lima, Peru: Proyecto POLICY, 2005.

22. Diaz M, Reporte de Actividades: Grupos Focales con Mujeres Pobres, Lima, Peru: Iniciativa de Políticas en Salud, 2006.

23. Petrera M, Evaluación de la Inclusión de Atenciones de Planificación Familiar en los Planes de Beneficios del Seguro Integral de Salud, Lima, Peru: Iniciativa de Políticas en Salud, 2006.

\section{Acknowledgments}

The authors wish to acknowledge Roberto Lopez, Patricia Mostajo, Varuni Dayaratna, Rebecka Lundgren, Nancy Murray, Carol Shepherd and Gracia Subiria for reviewing drafts of this comment. The U.S. Agency for International Development (USAID) Health Policy Initiative provided partial funding for this project under contract GPO-I-01-05-00040-00. The views expressed in this comment are those of the authors and do not necessarily reflect the views of USAID or the U.S. government.

Author contact:jgribble@prb.org 